SÁNCHEZ VILLALÓN, Iván

@ ivansanchezvillalon@hotmail.com

\title{
Etiología y naturaleza de los trastornos alimentarios desde la teoría mimética de René Girard
}

\author{
Etiology and nature of eating disorders from the mimetic \\ theory of René Girard
}

René Girard, desde su teoría mimética, sostiene que la cultura nos impone un ideal de delgadez que llega a provocar en algunas personas trastornos alimentarios. Ante la escalada mimética que se desencadena, no existen barreras culturales capaces de contenerla. Estos fenómenos, específicos de nuestro tiempo, tienen una temporalidad determinada. El alcance de las dinámicas «anoréxicas y bulímicas» alcanza a todas las capas de la cultura. Desde este paradigma girardiano podemos entresacar orientaciones para la práctica clínica.

PALABRAS CLAVE: Girard, teoría mimética, psicología interindividual, trastornos alimentarios, anorexia, bulimia.

René Girard, from his mimetic theory, argues that culture imposes an ideal of thinness, which in some people provokes eating disorders. Before the mimetic escalation that is triggered, there are no cultural barriers capable of containing it. These phenomena, specific to our time, have a certain temporality. The scope of the "anorexic and bulimic» dynamics reaches all layers of culture. From this Giradian paradigm we can select guidelines for clinical practice.

KEY WORDS: Girard, mimetic theory, interdividual psychology, eating disorders, anorexia, bulimia.

La teoría mimética de René Girard (1923-2015 ${ }^{[1]}$, crítico literario y antropólogo francés, ha sido aplicada a muchos campos de las ciencias sociales. Aunque es considerado un «forastero» en el ámbito de la psicología clínica, en uno de sus trabajos más destacados trata de explicar aquellos mecanismos que inervan la cultura actual y que favorecen el desarrollo de la anorexia y la bulimia ${ }^{[2]}$, ampliando el foco respecto al modelo biomédico dominante. 


\section{LOS TRASTORNOS ALIMENTARIOS EN EL CONTEXTO DE LA PSICOLOGÍA INTERINDIVIDUAL}

\subsection{La psicología interindividual derivada de la teoría mimética de René Girard}

En 1961, René Girard reveló, en Mentira romántica, verdad novelesca (Girard, 1985), que el deseo es mimético, que se inspira en los deseos de los otros; es, en definitiva, un deseo de ser Otro. El autor explica que entre el sujeto que desea y el objeto deseado se interpone un «modelo», que puede ser un mediador interno (alguien íntimo y conocido), o bien un mediador externo (un personaje histórico, una entidad cultural o una tradición). Por ello, la relación que se establece entre el sujeto y el objeto no es directa, lineal, sino «triangular»: sujeto-modelo-objeto. El contagio que motiva el deseo, no solamente se dirige hacia lo que el modelo tiene, sino más radicalmente hacia lo que el modelo es. La ilusión consiste en creer que la posesión del objeto señalado dará al sujeto ese «plus de ser» que nos fascina del otro y que codiciamos.

La teoría mimética encuentra un nuevo ámbito de aplicación en 1978, cuando René Girard, Guy Lefort y Jean-Michael Oughourlian publican el libro-entrevista Things Hidden since the Foundation of the World. En esta obra acuñaron la expresión «psicología interindividual ${ }^{[3]}$, donde postulaban que el self del sujeto se conforma gradualmente a través de todos los deseos imitados a lo largo de su historia. La relación interindividual, en la que nace el deseo mimético, implica tres posibilidades. En primer lugar, cuando el sujeto toma al otro como un modelo, sin rivalidad, nos encontramos en el marco del aprendizaje y la amistad. Cuando el modelo manifiesta alguna oposición, aunque sea mínima, y el sujeto es incapaz de manejar esta oposición, el otro pasa a ser considerado como un rival o un obstáculo. Mientras que en la rivalidad la «mímesis de apropiación» le lleva a sentirse desafiado por los bienes del modelo, hasta el punto de luchar por arrebatárselos, en el último caso el deseo del discípulo de adquirir sus pertenencias o su ser será radicalmente imposible. Estas disposiciones, consideradas patológicas, se generan cuando el yo reclama la propiedad de su deseo y su anterioridad con respecto al deseo del otro, que, de hecho, lo había engendrado a través de la sugerencia mimética. La miseria de la condición humana radica en la dificultad de aceptar que yo soy un «otro" anterior a mí que me constituye. La cultura precisamente trata de protegernos de esta realidad, del reconocimiento de nuestra alteridad.

\subsection{La anorexia y la bulimia como enfermedades del deseo}

Girard (1996) sitúa el origen de los trastornos alimentarios en aquello que es más evidente: el deseo de perder peso ${ }^{[4]}$. Frente a esta visión simple, la modernidad entiende que los fenómenos humanos no son realmente lo que parecen, por lo que solo pueden ser explicados desde una o varias de las «hermenéuticas de la sospecha» popularizadas en los siglos XIX y xx (psicoanálisis, marxismo, feminismo, etc.).

El autor subraya que su postura debería ser aceptada con facilidad, en cuanto que la mayoría de nosotros somos esclavos de este imperativo cultural: queremos ser delgados. Ahora bien, dada la relación tan desordenada que tiene nuestra cultura con la comida ${ }^{[5]}$, no 
sorprende tanto el aumento de estos trastornos como el hecho de que tanta gente coma de forma más o menos normal, ya que dichas patologías solo afectan a un pequeño porcentaje de la población ${ }^{[6]}$. Girard responde, por un lado, aludiendo a la capacidad de adaptación de la naturaleza humana, que es capaz de sobreponerse a los «delirios culturales más extravagantes» (Girard, 1996, p. 19). Por otra parte, nos dice que, en la delgadez, al igual que en otras áreas, las personas son más o menos rivales, solo que en este campo elegido para competir las consecuencias para la salud pueden ser funestas (Anspach y Tacou, 2009).

Ahora bien, existe un continuo entre estos vaivenes «normales» y la anorexia y la bulimia. El paso a la patología se da cuando el fin pasa a justificar los medios, esto es, cuando se da tanta importancia al hecho de perder peso que se está dispuesto a cualquier cosa para conseguirlo. La persona afectada por un trastorno alimentario trata de reducir su consumo de calorías hasta alcanzar o superar el grado de delgadez impuesto como deseable, de forma mayoritaria, en un momento dado (Sidella, 2011). En el caso de la anorexia se trata de conseguir esta meta de forma directa, absteniéndose de comer, mientras que en la bulimia se busca de manera indirecta, comiendo cuanto le apetece y expulsando después la mayor parte de la ingesta.

Para Girard (1996), la anorexia es mimética en cuanto que desea imitar a esas «diosas ultradelgadas» que se pasean por los medios de comunicación. Precisamente, el jugueteo de estos ídolos con la autodestrucción refuerza su apariencia de divinidad. Las chicas compiten $^{[7]}$, pero no porque quieran atraer a los hombres, o a las mujeres en los casos mucho menos frecuentes de anorexia masculina; ningún hombre encuentra atractiva a una mujer esquelética. Se produce una escalada de transgresiones para tratar de superar a sus contrincantes en flaqueza. En este tipo de «lucha a muerte», el objeto, una vez más, desaparece, ya no tiene más importancia: hambre, instinto, necesidad, nutrición, sexualidad y hombres ya no existen $^{[8]}$. La imagen corporal se vuelve casi delirante, pues la paciente demacrada acaba afirmando que es gorda. El cuerpo se pierde de vista, sacrificado en el altar de la rivalidad: la amenorrea, la emaciación y, a la larga, las características sexuales secundarias desaparecen.

En esta batalla la persona genera una relación ambivalente con la comida. Por un lado, tiene mucho apetito dado el hambre que experimenta ${ }^{[9]}$, pero teme que si pica algo luego no pueda parar, es decir, que se convierta en bulímica, por lo que trata de no relajarse. Por otra parte, estas personas experimentan repugnancia ante la comida (náuseas por ejemplo), ya que pueden perder en un momento lo que tanto esfuerzo les ha costado.

Oughourlian (2008) plantea que la anoréxica busca ejercer el poder sobre los miembros de su familia, que se convierten en prisioneros, obligados a vigilar a la paciente para controlar las calorías que consume..., o no. Su plato de comida sería como un circo romano donde confluyen dos deseos rivales: el de aquellos que la rodean, que quieren que coma, y ella que se niega a hacerlo (Anspach y Tacou, 2009).

En cuanto a las personas con bulimia, Girard (1996) nos dice que son candidatas a ser anoréxicas que, convencidas de no poder conseguirlo, se pasan al otro extremo, buscando eliminar de forma artificial los efectos de sus persistentes fracasos; por ello tienen un mejor pronóstico. Oughourlian (2016) distingue dos clases; un primer tipo serían anoréxicas, en cuanto que quieren adelgazar, pero su deseo rival es demasiado débil, ambivalente; la otra variedad son las bulímicas obesas, que comen para llenar un vacío y apaciguar su angustia. En estas pacientes, el deseo exagera la necesidad y borra el instinto normal de saciedad. 
Dentro de los medios para alcanzar la esbeltez, Girard (1996) hace alusión al ejercicio físico, que no pone en peligro la salud y no implica la pérdida del «respeto hacia uno mismo» (Girard, 1996, p. 5). El antropólogo sostiene que la única motivación de la gente para «ejercitarse" es perder peso, y no el contacto con la naturaleza o el fomento de la vida sana, como se proclama desde la esfera de lo políticamente correcto. Por otro lado, Girard (1996) explica que la incorporación al tabaquismo o la negativa a dejarlo, a pesar de las campañas gubernamentales, provienen del temor al aumento de peso, temor que los propios gobiernos, paradójicamente, fomentan.

\section{LA NATURALEZA MIMÉTICA DE LOS TRASTORNOS ALIMENTARIOS}

\subsection{El origen de los trastornos alimentarios ante una cultura sin prohibiciones}

Girard sitúa el origen de los trastornos alimentarios en el cambio cultural, que trajo consigo la «disolución de todas las prohibiciones» sociales y religiosas, lo que provocó, a su vez, la «intensificación de la rivalidad mimética» (Girard, 1996, p. 7).

Dentro de la sociedad, el autor nos habla en dos sentidos de los trastornos alimentarios en relación con la familia, que es una barrera homeostática contra el cambio social. La «familia individual», es decir los padres, son factor causal de estas patologías, en cuanto que transmiten la cultura del entorno; la «familia como entidad sociocultural», por su parte, contribuye a ellas en la medida en que está perdiendo su autoridad.

Por otra parte, una vez abandonados los principios religiosos y éticos, como ha ocurrido en Europa desde la llustración, nos quedamos en una sociedad totalmente materialista, en la que dependemos solo de nosotros mismos. Girard presenta los trastornos alimentarios como fenómenos inseparables de este individualismo dominante, que nos impele a desear ser los números uno. Cuando echamos una mirada hacia fuera tomamos conciencia de que estamos confundidos en la multitud; lejos de ser los primeros, siempre hay alguien que nos supera en cualquier aspecto, sea el físico, la inteligencia, la salud o, quizá como único ideal contemporáneo compartido, la flaqueza.

Este deseo mimético, que persigue conseguir la delgadez absoluta de algún ser deslumbrante a nuestros ojos ${ }^{[10]}$, convive con la falta de «admiración» que tenemos hacia nosotros mismos. La mímesis es un factor catalizador; convierte en normativo aquello que se ve en los otros. Así, el egocentrismo del deseo está unido a su altercentrismo, a su estar centrado en el otro. La persona con bulimia come para sí, pero vomita para que la vean los demás ${ }^{[11]}$; es algo dirigido contra la sociedad, contra la educación que ha recibido. «Se trata de algo muy visual, asociado a la mirada del otro", del cual creen que emana su ser (Anspach y Tacou, 2009, p. 77).

Esta es la consecuencia del proceso que «primero negó a Dios, luego al hombre y finalmente al individuo» (Girard, 1996, p. 9). La desaparición de la religión ha desembocado en infinidad de caricaturas de la religiosidad, dando lugar a multitud de dioses creados por nosotros, totalmente dependientes de nuestro deseo mimético, como es la búsqueda de la delgadez a toda costa. Ante la falta de una auténtica religión, «terminamos reinventando amos aún más feroces que el Dios del cristianismo más jansenista» (Girard, 1996, p. 8). 
Junto a la falta de valores también constatamos una carencia de ritos, que antes prescribía la religión (el ayuno en cuaresma). Girard considera que es muy probable que la anorexia en la adolescencia esté vinculada al hecho de que, en nuestro mundo, no existe ningún rito de paso a la adultez, lo que conduce a los jóvenes a autoimponérselos inspirándose en algún modelo. Por su parte, la sociedad moderna también genera nuevos ritos, como pueden ser «los piercings, los tatuajes...» (Anspach y Tacou, 2009, p. 79).

Por lo tanto, nuestros problemas no tienen su origen en la dificultad de apartarnos de nuestra tradición religiosa, sino precisamente en su debacle. Girard (1996) destaca que las personas que sufren este tipo de trastornos no son las «especialmente religiosas, tradicionalistas o fundamentalistas», sino que suelen ser las más «liberadas» (p. 7). Ahora bien, es importante aclarar que «no existe continuidad entre nuestros trastornos alimentarios y nuestra religión» (Girard, 1996, p. 9). El caldo de cultivo de estos trastornos es, aparte de lo dicho, el neopaganismo de nuestra época, el culto al cuerpo y la mística dionisíaca de Nietzsche.

Esta falta de contención cultural conduce a una sociedad indiferenciada, donde las categorías antropológicas esenciales han entrado en crisis, surgiendo rivalidades en torno a metas tan triviales como la delgadez. Por ejemplo, la diferencia en torno al sexo ha quedado difuminada; pensemos en los cánones de moda para hombres, tradicionalmente centrados en la virilidad, que proponen en los últimos tiempos chicos filiformes. De un modo parecido, la diferencia según edades también se desvanece, queriendo los jóvenes comportarse como personas adultas, y los adultos como si fueran jóvenes.

\subsection{La escalada mimética desde la dinámica del consumo de ostentación}

El fin de las prohibiciones arriba descrito, y la sociedad sin diferencias que va generando, acarrea una escalada mimética que vamos a explicar desde la dinámica del consumo de ostentación propuesta en el trabajo de Thorstein Veblen ${ }^{[12]}$. Este sociólogo, en un primer momento, hace notar que la exhibición de las propias riquezas ha sido siempre lo más importante para los nuevos ricos, los cuales han proliferado en Estados Unidos como en ningún sitio. Como eran inmigrantes, o descendientes de inmigrantes, no procedían de familias antiguas y destacadas, por lo que el único instrumento de presunción que tenían era el dinero.

Una vez que se acostumbran a su riqueza y se convierten en ricos veteranos, pierde su interés el consumo de ostentación y se pasan a un no-consumo de ostentación que, aun pareciendo una actitud contraria a la que sustituye, es un escalón superior del mismo desarrollo mimético. En nuestra sociedad podemos constatar muchos ejemplos de este no-consumo de ostentación, por ejemplo, en la ropa (vaqueros desgastados, pantalones caídos o el rechazo al vestido formal). Más allá de una interpretación políticamente correcta del fenómeno, que aludiría a la culpabilidad que sienten los ricos por sus muchas posibilidades económicas, que los llevaría a, por lo menos, parecer pobres, se trataría más bien de una actitud de indiferencia hacia la ropa, un rechazo notable de la ostentación. El hecho de privarse voluntariamente de algo es una demostración final de la superioridad de uno respecto a ese objeto y a quienes lo ambicionan. Podría existir un último escalón entre aquellos muy ricos que ya no se pueden permitir ser más materialistas, que consistiría en rechazar completamente la competición, y esta podría ser la competición más exacerbada. 
Podemos tener la impresión de que este proceso mimético surge de forma consciente, cuando en realidad es un proceso automático. En este sentido, Girard señala que la naturaleza se refuerza a sí misma: «Las modas no suelen tener sentido, son simplemente imitadas sin que quienes imitan reflexionen sobre su significado, lo cual no les impide seguirlas. El individuo se convierte en el vehículo de un significado que se le escapa» (Anspach y Tacou, 2009, p. 82).

\subsection{Los modos y dinámicas de la rivalidad a partir del potlatch}

Girard profundiza en el significado del no-consumo de ostentación, en la indiferencia ante el objeto, recurriendo al potlatch, que no deja de ser una forma paradójica de la mímesis. Los jefes de las tribus del noroeste de América solían hacer alarde de su superioridad entregando sus bienes más preciados a los jefes adversarios. El objetivo era superar al contrincante en el «desprecio a la riqueza», resultando ganador el que se deshacía de más bienes y recibía menos. La institucionalización de este juego acabó con la destrucción, por parte de los grupos, de aquellos bienes que inicialmente intentaban traspasarse.

Este fenómeno norteamericano, interpretado desde el consumo de ostentación, es una réplica análoga de nuestro comportamiento actual con la comida. Un análisis pormenorizado ofrece luz sobre el papel que juega la rivalidad en nuestros comportamientos, en cuanto a los modos que adquiere y a las dinámicas que genera. En primer lugar, en el potlatch, el hecho de competir por alcanzar una mayor indiferencia hacia la riqueza, a partir del despilfarro de los bienes, pretendía una búsqueda de prestigio. Esto pone de manifiesto que la rivalidad es posible «en la renuncia más que en la adquisición, en la privación más que en el placer» (Girard, 1996, p. 11) ${ }^{[13]}$. Entendemos que el binomio renuncia-privación se refiere a la anorexia, y la pareja adquisición-placer a la bulimia ${ }^{[14]}$. En esta línea argumentativa, Girard (1996) sostiene que subdividir los trastornos alimentarios en entidades clínicas separadas es algo artificioso y superficial, ya que, en nuestro mundo, comer demasiado, como en el caso de la bulimia, o comer de forma insuficiente, aludiendo a la anorexia, son modos opuestos pero inseparables de afrontar el precepto de la delgadez que dicta nuestra cultura ${ }^{[15]}$.

Por otro lado, la ilegalización del potlatch en Canadá, debido a que esta pretensión de prestigio solo beneficiaba a los jefes supremos y traía consecuencias negativas para gran parte del pueblo, revela que, para una colectividad, siempre son más peligrosos los modos negativos de buscar el prestigio (anorexia) que los positivos (bulimia), los cuales no afectan tanto a las necesidades básicas de las personas.

\section{LA HISTORICIDAD DE LOS TRASTORNOS ALIMENTARIOS}

\subsection{La temporalidad de la escalada mimética}

Los expertos reconocen la dimensión mimética de los trastornos alimentarios, pero conciben la imitación al modo del siglo xIx, esto es, como un «mero contagio social pasivo». No perciben «la dimensión competitiva, la escalada mimética en su conjunto», por eso no se percatan de que se trata de un «fenómeno histórico» con una temporalidad propia (Girard, 1996, p. 12). 
El comienzo de este furor por la delgadez tiene que ver con la vida de dos distinguidas y bellas mujeres, de clase alta: Isabel de Austria, conocida como «Sissi», esposa del emperador Francisco José, y Eugenia de Francia, mujer de Napoleón III. Se cuenta que, en alguna ocasión, cuando sus maridos se encontraban, ellas se retiraban a una sala aparte para comparar sus respectivas siluetas. Este episodio de incipiente rivalidad entre ambas supone el establecimiento de un «patrón de competición mimética», que las damas de la alta sociedad copiaban al detalle. Es interesante apuntar que se redactaron las primeras descripciones clínicas de la anorexia cuando estas mujeres ejercían su mayor influjo[16].

La escalada mimética se ha extendido e intensificado desde entonces ${ }^{[17]}$, llegó a la clase media después de la Primera Guerra Mundial, y alcanzó a todas las clases, al menos en la sociedad desarrollada occidental, después de la Segunda Guerra Mundial (Girard, 1996). Ahora bien, el modo de vida de «Sissi», típico de la anorexia (dietas rigurosas bajas en calorías o ejercicio físico intenso), ha virado en la actualidad a un patrón más bien bulímico, mejor considerado a nivel social. La evolución de estas patologías tiene que ver con la intensificación de la rivalidad a medida que aumenta el número de imitadores, disminuyendo el peso considerado ideal. Esta tendencia alcanza a muchos ámbitos de nuestra actividad, como puede ser la distorsión de los criterios a la hora de seleccionar a una persona para un puesto de trabajo, con la discriminación que lleva consigo considerar más valiosas a las mujeres delgadas ${ }^{[18]}$.

Como fin de esta evolución pensemos que, si las tendencias y las modas se desarrollan de forma dinámica, es porque lo hacen de manera mimética. Así, el espíritu competitivo puede imponerse, aunque no haya ningún rival concreto. Cuando la competición se nutre solo de sí misma, más allá de los objetos que la motivaron en un origen, se alcanza el estadio de crisis, que se caracteriza por la competición de las personas entre sí, con el único objetivo de competir.

\subsection{La distorsión del pasado: Europa, el arte y el ascetismo}

En otro sentido, Girard (1996) constata que proyectamos nuestra obsesión por la comida en el pasado, atribuyéndole el imperativo de la gordura, con dos objetivos: por un lado, deploramos reconocer nuestras idas y venidas miméticas, y disfrutamos señalando la mímesis en los otros; por otro, nos cuesta darnos cuenta de la singularidad de nuestra cultura, que es la más obsesionada con la comida en la historia occidental; pensemos en la cantidad de programas de televisión, libros o revistas que tienen que ver con la alimentación. Esta distorsión del pasado la desarrollamos a partir de mentiras o medias verdades, referidas a tres ámbitos. En primer lugar, se tiende a sostener que, en Europa, se preferían las mujeres gruesas, porque el estado de casi inanición imperante derivaba en una obsesión por la comida. Esta teoría no se corresponde con la realidad ni desde el punto de vista histórico ni estético ${ }^{[19]}$. En segundo lugar, no encontramos en la historia de la pintura nada parecido a «nuestra preocupación por el peso adecuado de una mujer» (Girard, 1996, p. 15). En siglos anteriores al nuestro había distintos gustos, tanto en las escuelas pictóricas como en los pintores individuales. Por último, está sesgada la interpretación que damos hoy al «ayuno sagrado» como «una forma incipiente de anorexia» ${ }^{[20]}$ (Girard, 1996, p. 15). Ciertamente, pudieron darse casos puntuales de un falso ascetismo entre aquellos que deseaban, más que alcanzar la santidad, ser conside- 
rados como santos, pero la Iglesia, consciente de la posibilidad de estas desviaciones, vigilaba para evitarlas.

\subsection{Los trastornos alimentarios como fenómenos específicos de nuestra cultura}

La epidemia sobre los trastornos alimentarios tiene mucho que ver con la cultura y su deriva, alcanzando en estos momentos su cénit. Los especialistas suelen referirse a ellos solo en términos médicos pues, como afirma Girard (1996), «idolatran los mismos ídolos que sus pacientes» (p. 16).

En nuestro mundo desarrollado, las fuerzas que nos incitan a consumir y las que nos impulsan a dejar de comer son igual de poderosas: el consumo excesivo, la comida a bajo precio o la presión publicitaria. Así, la cultura parece haber provocado una conspiración que trata de evitar que alcancemos las metas que, a su vez, nos asigna. Girard (1996) sostiene que estos mensajes ambivalentes crean una paradoja que amenaza con atrapar a las personas en la desesperanza, provocada por el agotamiento y el aburrimiento. En esta discusión, parece fácil y predecible apuntar al capitalismo como culpable, en cuanto que trata, por ejemplo, de ofrecernos productos que supuestamente pueden ayudarnos en esta batalla; pero Girard lo considera un actor secundario que se acomoda de forma reactiva a nuestra ansia de estar delgados, en lugar de imponerse activamente (Strand, 2018).

\subsection{El alcance de la epidemia a todos los ámbitos de la cultura}

Proponemos un breve itinerario por las dinámicas propias tanto de la modernidad como de la posmodernidad, para comprobar cómo estas distorsiones han ido afectando a todas las esferas culturales hasta alcanzar la alimentación, que es el tema que nos ocupa.

Las artes, sean cuales fueren, han sido dominadas por los ideales de radicalismo y revolución que, en realidad, implican una escalada competitiva que consiste en despreciar aquellos «principios y prácticas heredados de cualquier arte» (Girard, 1996, p. 17). Es paradójico que las nuevas generaciones, enarbolando la bandera antimimética, imiten a sus predecesores en la ruptura con cualquier aspecto que todavía los anteriores no hubieran desechado. Aunque estos recién llegados se jactan de ser los auténticos revolucionarios, acaban imitándose entre ellos. Ciertamente, esta dinámica ha experimentado interrupciones puntuales o incluso alguna breve inversión en la historia moderna, pero el impulso base es incuestionable.

Un sucinto recorrido por algunas de las artes dará cuenta de lo dicho. En la pintura, se fueron descartando primero la «representación realista de luces y sombras», luego se fueron abandonando «elementos cada vez más esenciales, como la perspectiva tradicional» (Girard, 1996, p. 17), para terminar con cualquier forma reconocible o el propio color. La evolución en arquitectura y en artes decorativas fue similar. En la poesía se dejó de lado la rima y luego el resto de los elementos de la métrica. Así, podemos definir la corriente generalizada de la modernidad como minimalista. Este proceso encuentra su correlato en el resto de los géneros de la literatura (novela, teatro, etc.). Se va prescindiendo paulatinamente del contexto realista, 
después de la trama, a continuación de los personajes, para acabar con frases incoherentes y la sustitución de las mismas palabras por revoltijos de letras. Es cierto que no todas las escuelas se desprenden de los mismos elementos a la vez, pero la tendencia general de todo y todos hacia la nada en el ámbito artístico es fruto del «temperamento anoréxico de nuestra época» (Girard, 1996, p. 18).

Girard se refiere a estas obras para poner de relieve que estas tendencias anoréxicas ya estaban presentes en nuestra cultura mucho antes de que ejercieran su influjo sobre la alimentación. Así, debemos interpretar la preeminencia actual de los trastornos alimentarios como un momento de particular manifestación de lo que nos ocurre, sin necesidad de reducirlo a una epidemia azarosa.

La posmodernidad ha dejado atrás estos planteamientos, sustituyendo el fetiche de la innovación a cualquier precio por un «eclecticismo caótico» (Girard, 1996). El talante posmoderno se nutre de cualquier cosa pasada, sin ningún propósito identificable y, paradójicamente, no le reconoce ningún valor (pensemos en el desprecio a la imitación de los clásicos). Dado que vomita rápidamente lo que engulle de forma indiscriminada, podríamos decir que los intelectuales y artistas están imbuidos del espíritu bulímico que nos circunda.

Sea como fuere, la escalada no ha terminado...

\section{UNA ORIENTACIÓN PARA LA PRÁCTICA CLÍNICA DESDE LA ANTROPOLOGÍA GIRARDIANA}

\subsection{Radiografía de la posmodernidad}

La relación con los alimentos tiene mucho que ver con la identidad de la persona, la cual queda comprometida por las influencias que recibe de la cultura circundante. El self moderno se conforma así de manera «adaptativa» o «de afuera hacia dentro», y no «espontánea» o de «adentro hacia afuera» (Lawtoo, 2013). El estándar social dominante dicta los comportamientos y roles «buenos» 0 «malos», que están íntimamente relacionados con el concepto de «verdad», que ha sufrido un viraje en los últimos tiempos. La modernidad, por un lado, identificó la verdad con una presunción de neutralidad intelectual, que asoció automáticamente con el racionalismo escéptico. La posmodernidad nietzscheana, por su parte, descartó lo anterior y asumió que la verdad es una construcción social: no hay verdad; solo tu verdad y mi verdad.

Esta situación genera camaleones sociales, personalidades pastiche, fragmentadas e inestables, compuestas de los distintos fragmentos prestados de cualquier fuente disponible. La desestructuración resultante genera síntomas de angustia psicológica, al vivir en una permanente «casa de los espejos», que los sujetos tratan de aliviar recurriendo al arsenal farmacológico.

\subsection{Hacia una regulación del deseo}

El «yo moderno» tiene dificultades para aceptar que es fruto de una «colonización» por parte de los otros, y trata de dárselas de original, luchando por imponer que su deseo es 
esencialmente autónomo. El personaje más famoso que encarna esta idolatría de autosuficiencia fue Rousseau. Su afán era impresionar a los demás para despertar su adulación, demostrando de forma convincente su completo desinterés por ella (Bailie, 2006).

Bailie (2006), por otra parte, nos relata la experiencia de Descartes que, durante el invierno holandés de 1628, se instaló en un pequeño desván con el fin de meditar sobre sus propios pensamientos, alejado de toda compañía, para aislarse de la sugerencia mimética ${ }^{[21]}$. La cautela es legítima, pero el deseo mimético es quien hace de la humanidad una criatura dotada de un deseo de realizarse a sí misma al estar bajo la influencia de otro. Descartes anticipa la desesperada autorreferencialidad del yo moderno, y sus esfuerzos melancólicos por lograr una autenticidad cada vez más inalcanzable.

Por otro lado, don Quijote es un hombre que sufre una crisis espiritual y psicológica, similar a la descrita en los casos anteriores. Este caballero trata de responder a este malestar imitando al héroe ficticio de las novelas de caballería, Amadís de Gaula. El protagonista de la novela de Cervantes tiene un momento de verdad en el que se despierta y, después de pasar una vida emulando a su modelo, en su lecho de muerte, recobra sus sentidos ${ }^{[22]}$. Al darse cuenta de que su vida se había malgastado imitando servilmente a un modelo cuyas aventuras no merecían tal atención, don Quijote no renuncia a la imitación, como lo harían sus herederos modernos, sino que lamenta el hecho de que su muerte inminente le deje tan poco tiempo para compensar su error leyendo esos otros libros que podrían iluminar su alma.

\subsection{Aplicaciones en el campo clínico}

Antes de entrar en el terreno clínico, vamos a subrayar algunas tesis que se derivan de lo dicho hasta ahora. Por un lado, parece claro que el estudio de la patología mental no se puede limitar a la persona, o incluso a la familia. Dado el poder formativo de la mímesis, es necesario considerar el campo social más amplio que circunda al sujeto (el macrosistema, que diría Bronfenbrenner), considerando las influencias culturales.

Por otra parte, en cuanto a la etiología, realmente no sabemos qué causa particular provoca un trastorno alimentario y, en la mayoría de los casos, no importa, al menos en las etapas iniciales del tratamiento (Lock y Le Grange, 2013; citado por Strand, 2018). Girard (1995) refiere que se trata de una especie de «posesión» por parte del «espíritu de la delgadez antinatural».

Además, se ha puesto de manifiesto que estar inmerso en este imperativo cultural de esbeltez no es suficiente para desarrollar un trastorno alimentario. El propio Girard apunta a otros factores individuales no especificados como desencadenantes de la patología, descartando así una perspectiva determinista de su paradigma.

Podemos extraer dos orientaciones para la prevención desde la psicología interindividual, una a nivel terciario y otra a nivel secundario. En cuanto a medidas dirigidas a toda la población, sería importante promover una «alfabetización» mediática, que permita a los sujetos cribar las informaciones que reciben y elaborarlas de forma crítica. Respecto a colectivos en riesgo, podemos alentar a los sujetos a tomar una postura que sea contraria a su actitud original, para generar una disonancia cognitiva que promueva la reflexión y pueda conducir a un cambio de actitud (Watson et al., 2016; citado en Strand, 2018). 
Como medidas aplicadas a los afectados por trastornos alimentarios, deberíamos empezar a trabajar con los rasgos que pueden agravar la influencia de la rivalidad mimética, hasta llegar a un punto donde el individuo pierde el control de la situación y desarrolla la patología; pensemos, por ejemplo, en la distorsión de la autoimagen. Estas personas tienden al sesgo cognitivo de juzgarse a sí mismas únicamente por su capacidad para controlar los hábitos alimentarios, el peso y la forma. Para contrarrestar esta tendencia, podríamos sugerirles que realizaran un gráfico circular, donde pudieran estimar la importancia subjetiva de las diferentes partes de su vida (relaciones, escuela, trabajo, deportes, ocio, forma corporal, etc.) (Strand, 2018).

El trabajo de la autoestima es otro de los elementos que se van a trabajar en terapia, ya que la anorexia y la bulimia son una forma de «auto-chivo-expiación». La tortura que el sujeto se inflige no comiendo, es una forma de expiar algo que no le gusta de sí mismo, de lo cual la gordura es una pequeña manifestación (Anspach y Tacou, 2009). Además, presenta dificultades de regulación emocional, y llega a experimentar, simultáneamente, estados afectivos negativos, como la pérdida de control, y sentimientos de orgullo o de logro, al recompensar aspectos del trastorno.

Siguiendo con la intervención, sabemos que los estilos educativos parentales se mueven en torno a dos parámetros, afecto y control. Estas dimensiones aparecen trastocadas en las familias con una persona afectada por estas patologías. Por un lado, el sujeto trata de hacer triunfar su voluntad de no comer sobre los esfuerzos que hacen sus familiares y médicos por alimentarla. Así, en esta rivalidad en la que se encuentran inmersos tanto ella como su familia, tiene asegurada la atención por parte de sus cercanos. Sería importante que aprendiera otras formas para demandar afecto que no pusieran en peligro su vida. En otro sentido, la persona rechaza la comida como medio para demostrar control sobre las necesidades biológicas, que es una manera de controlar una vida que no comprende. Por ello, parece necesaria una terapia que vaya más allá de lo conductual para ayudarla a afrontar este desconcierto.

En otro sentido, la abstención de algo, en este caso de la comida, manifiesta independencia y deseo de valerse por sí misma, que son poderosos generadores de rivalidad mimética. Esta paciente, en plena adolescencia, pretende culminar el proceso de diferenciación de su familia de origen, algo en principio necesario. La paradoja en cuestión es que, al pretender distanciarse con esta patología que compromete tanto su salud, no consigue separarlos ni un momento de su lado. Deberíamos explorar cómo manejan los límites y normas en su entorno, de manera que se pudiera reforzar la capacidad de decisión de la paciente, canalizando ese deseo de autonomía de forma adecuada. En esta línea, nos parece importante también resolver su paradoja, ayudándole a caer en la cuenta de que la autosuficiencia no implica la independencia absoluta de los demás; la dicotomía se resuelve en un punto medio entre los dos extremos.

Para terminar, volvamos a Cervantes, que constata que la imitación es un hecho ineludible en la vida humana, y que la elección crucial es a quién toma uno como modelo. La conversión en el lecho de muerte del héroe de La Mancha consistió en darse cuenta de que había imitado al modelo equivocado, y deseaba querer imitar a los buenos modelos, los santos, que es seguramente lo que quiere decir Cervantes cuando habla de libros que son «luz del alma».

Los modelos desviados se convierten para el paciente en ídolos, imágenes de culto; estos rivales llevan a la persona a generarse un «yo ideal», en oposición al «yo real». El modelo adecuado al que deberían imitar estos pacientes podríamos definirlo como un icono, alguien que les guiará en la forma adecuada de quererse y tratarse, llevándolos a la aceptación de sí 
mismos tal y como son. La terapia debe ir dirigida a incitarles a buscar estas buenas referencias y a sugerirles que miren hacia donde ellos miran. Esta puntualización es importante: si se quedan fijadas en el modelo, podría desencadenarse la ya manida escalada mimética, y acabaría siendo una competición feroz contra uno mismo, sin más modelo que el narcisismo; la propia persona con anorexia o bulimia se convertiría en modelo y mediador.

Las personas con trastornos alimentarios se miran en el espejo de un mundo que les espeta: «No te van a aceptar; no estás a la altura, etc.». La posición del terapeuta, por el contrario, debe ser de acogida incondicional, tiene que hacerle ver la perfección de su ser tal como es, y señalarle la comparación con otros como la causa de su problema.

\section{Conclusión}

La aplicación de la teoría mimética tiene una pretensión omnicomprensiva que suele levantar sospechas. Girard responde señalando, por un lado, que, si bien no es «aplicable a todas las relaciones humanas", es necesario "ser consciente de los mecanismos que describe» (Anspach y Tacou, 2009, p. 81); por otra parte, entiende que cada persona es única, que debemos remitirnos a factores individuales para explicar por qué solo algunos llevan hasta la patología el ideal de una figura filiforme (Anspach y Tacou, 2009).

Además, se ha puesto de relieve que la esencia del sujeto occidental es la identidad entre lo que es y lo que ve. Desde ahí hemos constatado el papel crucial, pero no exclusivo, de la cultura en los trastornos alimentarios. Ahora bien, parece que el mensaje mundial no es que tenemos que adelgazar, sino que lo común son las fuerzas miméticas que están operativas en todas las sociedades y contextos ${ }^{[23]}$.

Esta situación nos ha abocado a un individualismo que resulta ser paradójico. Cuanto más se postula la primacía del hombre sobre la colectividad, más posee la colectividad el espíritu individual. Por ello, en el origen del individualismo, no está seguramente una desaparición de la mímesis, sino una exasperación de la misma.

La perspectiva de futuro no es muy esperanzadora. Se va imponiendo una consideración de la anorexia y la bulimia como formas de autocuidado, enmarcándolas en un saludismo, culturalmente aceptado, que promueve la dieta constante y el ejercicio físico como partes de un estilo de vida healthy. Este planteamiento pierde de vista las nefastas consecuencias en los ámbitos cognitivo, emocional, físico y conductual de estos pacientes. Más allá de suponer un control sobre nuestro cuerpo, son precisamente una pérdida de control sobre el mismo. No estamos, por tanto, ante algunas patologías desencadenadas por la debacle de la cultura, sino ante una cultura patologizada.

\section{RefERENCIAS BibLIOGRÁFICAS}

American Psychiatric Association. (2013). Diagnostic and statistical manual of mental

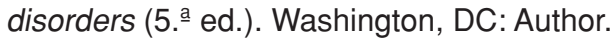

Anspach, M. R. y Tacou, L. (2009). Una conversación con René Girard. En R. Girard, La anorexia y el deseo mimético (pp. 61-95). Barcelona: Marbot. 
Bailie, G. (2006). The Imitative Self: The Contribution of René Girard. En G. Bailie, The self: Beyond the postmodern crisis (pp. 3-23).

Barahona, A. J. (2011). René Girard: De la ciencia a la fe. e-Xaverius, 1, 6-34. Recuperado de http://www.asociacioneuc.org/e-xaverius/e-xaverius_01.pdf.

Bruch, H. (1973). Eating Disorders: Obesity, Anorexia Nervosa, and the Person Within. Nueva York, NY: BasicBooks.

Cervantes, M. (2005). El ingenioso hidalgo Don Quijote de la Mancha. Barcelona: Planeta.

Festinger, L. (1954). A Theory of Social Comparison Processes. Human Relations, 7(2), 117-140. Fitzsimmons-Craft, E. E., Bardone-Cone, A. M., Bulik, C. M., Wonderlich, S. A., Crossby, R. D. y Engel, S. G. (2014). Examining an Elaborated Sociocultural Model of Disordered Eating among College Women: The Roles of Social Comparison and Body Surveillance. Body Image, 11(4), 488-500. Recuperado de http://bardonecone.web.unc.edu/ files/2014/10/Fitzsimmons-Craft-et-al-2014.pdf.

Girard, R. (1985). Mentira romántica y verdad novelesca. Barcelona: Anagrama.

- (1995). La violencia y lo sagrado. Barcelona: Anagrama.

- (1996). Eating Disorders and Mimetic Desire. Contagion: Journal of Violence, Mimesis, and Culture, 3, 1-20. Michigan State University Press. Recuperado de https://msu.edu/ course/eng/473/johnsen/3.Girard.pdf.

Hruschka, D. J., Brewis, A. A., Wutich, A. y Morin, B. (2011). Shared Norms and Their Explanation for the Social Clustering of Obesity. American Journal of Public Health, 101(S1), S295-S300. Recuperado de https://www.ncbi.nlm.nih.gov/pmc/articles/ PMC3222514/pdf/S295.pdf.

Lawtoo, N. (2013). The Birth of the Ideal Ego. En N. Lawtoo, The Phantom of the Ego: modernism and the mimetic unconscious (pp. 162-181). United States of America: Michigan State University Press.

Leahey, T. M., Crowther, J. H. y Mickelson, K. D. (2007). The Frequency, Nature, and Effects of Naturally Occurring Appearance-Focused Social Comparisons. Behavior Therapy, 38(2), 132-143.

Lock, J. y Le Grange, D. (2013). Treatment Manual for Anorexia Nervosa: A Family Based Approach. New York: Guilford Press.

Musher-Eizenman, D. R., Holub, S. C., Barnhart Miller A., Goldstein, S. E. y Edwards-Leeper, L. (2004). Body Size Stigmatization in Preschool Children: The Role of Control Attributions. Journal of Pediatric Psychology, 29(8), 613-620. Recuperado de https://academic. oup.com/jpepsy/article/29/8/613/966811.

Ortuño, F. (2010). Lecciones de psiquiatría. Madrid: Panamericana.

Oughourlian, J. M. (2008). Préface. En R. Girard, Anorexie et désir mimétique (pp. 7-13). Éditions de L'Herne.

- (2016). The Mimetic Brain. United States of America: Michigan State University Press. Russell, G. (1979). Bulimia Nervosa: An Ominous Variant of Anorexia Nervosa. Psychological Medicine, 9(3), 429-448.

Schaefer, D. R. y Simpkins, S. D. (2014). Using Social Network Analysis to Clarify the Role of Obesity in Selection of Adolescent Friends. American Journal of Public Health, 104(7), 1223-1229. Recuperado de https://www.ncbi.nlm.nih.gov/pmc/articles/PMC4056220/pdf/ AJPH.2013.301768.pdf. 
Sidella, R. (2011). Anoressia e mimesi secondo René Girard. Rivista Internazionale di Filosofia e Psicologia, 2(1), 66-73. Recuperado de https://www.rifp.it/ojs/index.php/rifp/ article/download/rifp.2011.0007/65.

Skärderud, F. (2007). Eating One's Words, Part II: The Embodied Mind and Reflective Function in Anorexia Nervosa-Theory. European Eating Disorders Review, 15(4), 243-252. Recuperado de http://citeseerx.ist.psu.edu/viewdoc/download?doi=10.1.1.510.1868\&rep=rep1\&type $=$ pdf.

Strahan, E. J., Wilson, A. E., Cressman, K. E. y Buote V. M. (2006). Comparing to Perfection: How Cultural Norms for Appearance Affect Social Comparisons and Self-Image. Body Image, 3(3), 211-227. Recuperado de http://isiarticles.com/bundles/Article/pre/pdf/36946.pdf. Strand, M. (2018). René Girard and the Mimetic Nature of Eating Disorders. Culture, Medicine, and Psychiatry, 42 (3), 552-583. Recuperado de https://doi.org/10.1007/s11013018-9574-y.

Veblen, T. (2008). Teoría de la clase ociosa. Madrid: Alianza.

Watson, H. J., Joyce, T., French, E., Willan, V., Kane, R. T., Tanner-Smith, E. E. McCormack, J., Dawkins, H., Hoiles, K. J. y Egan, S. (2016). Prevention of Eating Disorders: A Systematic Review of Randomized, Controlled Trials. International Journal of Eating Disorders, 49(9): 833-862.

Wilson, E. (2003). Adorned in Dreams: Fashion and Modernity. Londres, UK: I.B. Tauris and Co.

\section{NOTAS}

[1] René Girard nació en Avignon (Francia). Cuando terminó la Segunda Guerra Mundial se marchó a Estados Unidos a estudiar historia, literatura y cultura medieval francesa, y ejerció su docencia en la John Hopkins University y en la Universidad de Stanford. Es doctor Honoris causa en varias universidades del mundo. Su trabajo intelectual arranca en 1950, interesándose por los dilemas morales de escritores existencialistas, como Sartre, Camus y Malraux. Posteriormente, se centró en la literatura, la filosofía, la antropología y el psicoanálisis, asociándose a las corrientes estructuralistas y postestructuralistas (Lévi-Strauss, Barthes, Lacan, Derrida y Focault). El renombre internacional lo alcanza a partir de su trabajo en 1970 en el campo de la fenomenología de las religiones, con su teoría del deseo mimético, el mecanismo del chivo expiatorio, la violencia y su relación con lo sagrado (Barahona, 2011).

[2] En el Diagnostic and Statistical Manual of Mental Illness (2013) se caracteriza la anorexia nerviosa como la restricción de la ingesta de alimento que conduce a un peso corporal significativamente bajo, un miedo intenso al aumento de peso y una experiencia distorsionada del propio peso o forma corporal. Por otra parte, la bulimia nerviosa se describe por episodios de atracones recurrentes, comportamientos compensatorios inapropiados («purgas», como vómitos, uso inadecuado de laxantes o ejercicio excesivo") para prevenir el aumento de peso y un énfasis desproporcionado en el peso o la forma corporal a la hora de autoevaluarse.

[3] La teoría mimética, elaborada a finales del siglo xx, ha resonado en las investigaciones neurocientíficas más recientes. Por ejemplo, Meltzoff y Moore publicaron en 1977 sus resultados experimenta- 
les, donde constataron que los recién nacidos aprendían imitando los movimientos de la cara del experimentador. Más adelante, en 1996, llegó el descubrimiento de las neuronas espejo por parte del profesor Rizzolatti y su equipo. Estas neuronas actúan a nivel prerracional identificando los gestos de los otros e interpretando sus acciones e intenciones, con el fin de comprenderlas e imitarlas.

[4] La delgadez extrema se ha convertido en la actualidad en la condición indispensable para ser más deseable, aunque, como explica Tacou, existe allí una tendencia añadida a ser gorda y gruesa al mismo tiempo; pensemos en los pechos de silicona, o en los labios hinchados (Anspach y Tacou, 2009).

[5] En este sentido, las personas con bulimia, con sus atracones, llevan hasta la caricatura aquellos rasgos típicos de nuestra cultura relacionados con la falta de regulación de las comidas: consumir cantidades ingentes de comida basura, en solitario, sin un horario fijo y a toda prisa.

[6] A este respecto, tengamos en cuenta que la anorexia afecta a un 0,1-1 \% de la población, a nivel general, acercándose al $1 \%$ a medida que la población es más adolescente y de sexo femenino (Ortuño, 2010).

[7] Una limitación del trabajo de Girard, a nuestro juicio, es el sesgo de género que contiene. Si bien reconoce que tanto los hombres como las mujeres están afectados por los trastornos alimentarios, continúa su relato refiriéndose solamente a las mujeres. Valga como disculpa que hace casi veinticinco años, cuando publicó su trabajo, no estaba tan extendido como hoy la consecución del ideal de cuerpo masculino, que se busca desde la musculatura y no tanto desde la delgadez. Si tenemos en cuenta la prevalencia de anorexia nerviosa, se distribuye en un $90-95 \%$ de mujeres y un 5-10\% de varones.

[8] El deseo, que es mimético, se distingue radicalmente de la necesidad, del instinto y de los impulsos, y se revela capaz de pervertirlos, subvertirlos, o incluso suprimirlos. Así las cosas, una necesidad tan fundamental y básica como la nutrición es completamente evacuada, disociada del deseo, cuando las pasiones competitivas tienen prioridad sobre la salud física y psicológica.

[9] Para cualquier persona hambrienta, toda gira en torno a la comida; de ahí los altos niveles de ansiedad en los pacientes que sufren anorexia nerviosa, ya que sus cerebros desnutridos les obligan a pensar en la comida sin parar. Girard lo expresa diciendo que la motivación del «cada vez menos» puede sustituir a la motivación del "cada vez más», que al final significa lo mismo (Strand, 2018).

[10] Aunque, a menudo, los actuales modelos socioculturales no explican qué mecanismos provocan la internalización del ideal de delgadez que induce a una alimentación desordenada, se ha aislado como factor mediador la comparación social (Fitzsimmons-Craft et al., 2014; citado por Strand, 2018). Estas dinámicas miméticas se perciben en edad preescolar, como muestra el experimento de Musher-Eizenman, Holub, Barnhart Miller, Goldstein y Edwards-Leeper (2014). Cuando los investigadores entrevistaron a niños acerca de fotografías de coetáneos suyos con diferentes tipos de cuerpo, el niño gordito recibió la calificación más negativa y fue el menos elegido como posible compañero de juegos. Ahora bien, mientras que Festinger (1954), señala que los individuos se comparan entre sí para autoevaluarse, principalmente con personas similares a ellos, se ha demostrado que las mujeres se comparan con frecuencia con las imágenes poco realistas e inalcanzables que les ofrecen los medios, y continúan haciéndolo, aunque impacte de forma adversa en su salud (Strahan, Wilson, Cressman y Buote, 2006; Leahey, Crowther y Mickelson, 2007).

[11] Girard (1996) nos dice que si bien algunos romanos, allá por el siglo i a. C., se sobrealimentaban y vomitaban, lo hacían para ellos mismos, no para los demás como ocurre en la actualidad. 
[12] Veblen introdujo en la década de 1920 el concepto de «consumo de ostentación», para explicar el surgimiento de una tendencia a mantener el estatus social mediante la vivencia presuntuosa de los patrones de consumo, el tiempo libre, etc. Esta teoría ha sido criticada por ser demasiado simplista en la reducción del consumismo y la moda a dominios femeninos en gran medida irracionales, carentes de control y autonomía (véase, por ejemplo, Wilson, 2003; citado por Strand, 2018).

[13] Curiosamente, en su libro El misterio de nuestro mundo, publicado originalmente en 1978, casi dos décadas antes de participar en el debate en torno a los trastornos alimentarios, Girard reconoció la posibilidad de una variante invertida de la mímesis, como se ve en el potlatch. En aquel texto nos dice que la «mímesis de apropiación» se puede invertir en una «mímesis de renuncia» (lo descubre posteriormente en el cuerpo de la paciente con anorexia nerviosa). Esta última mímesis es capaz, como su opuesta, de alcanzar una intensidad funesta.

[14] Esta idea del cuerpo como escenario para la exhibición de «metáforas» no es nueva en la investigación de los trastornos alimentarios (Skärderud, 2007; citado por Strand, 2018). Sin embargo, se ha observado que tiende a manifestarse en pacientes con anorexia nerviosa; el «como si» de la metáfora se ha convertido en un «es», se ha hecho real: el paciente con anorexia nerviosa es su peso.

[15] El descubrimiento de la bulimia como una nueva enfermedad, a finales de la década de 1970, se atribuye a Russell, con su trabajo: «La bulimia nerviosa: una inquietante variante de la anorexia nerviosa» (Rusell, 1979). En efecto, su descripción de los síntomas de la bulimia habían sido ya mencionados en relación con la anorexia (Bruch, 1973).

[16] La primera descripción clínica de lo que hoy conocemos como anorexia nerviosa se realizó en 1689 de la mano del médico británico Richard Morton. Posteriormente, el médico francés Charles Lasègue y el británico William Gull definieron esta enfermedad como un trastorno alimentario. Unos años más tarde, con el concepto de anorexia ya establecido, Jean Martin Charcot señaló en 1889 que la motivación de estas pacientes para dejar de comer era el miedo a engordar. Casi un siglo más tarde, Hilde Bruch, psiquiatra y psicoanalista, añadió la distorsión de la imagen corporal como otro síntoma de la enfermedad. Finalmente, en 1980, la definición de anorexia nerviosa fue incluida en el DSM-III.

[17] Aunque se suele considerar el cambio como lo esencial de la moda, la tendencia a la delgadez sigue avanzando en la misma dirección desde hace más de cien años, aunque los criterios de belleza sí han evolucionado. Las «estrellas de Hollywood de los años 30" (Marilyn Monroe o Ava Gardner) serían regordetas según nuestros patrones, aunque en su momento se las consideraba delgadas, y desde los prototipos de la Primera Guerra Mundial eran totalmente flacas. La tendencia en los 40 era tal que no pudo aplacarla ni la hambruna de la Segunda Guerra Mundial (Girard, 1996; Anspach y Tacou, 2009).

[18] El estigma relacionado con el peso incluye a menudo juicios morales como pereza, irresponsabilidad, fealdad y falta de autocontrol. Además, las personas tienden a agruparse en función del índice de masa corporal, en parte debido a los comportamientos sociales como, por ejemplo, los que rodean el ejercicio (Hruschka et al., 2011; citado por Strand, 2018). Schaefer y Simpkins (2014) muestran que los adolescentes sin sobrepeso son más propensos a seleccionar amigos que no tienen sobrepeso, lo que deja a los adolescentes más gruesos con pocas opciones para convertirse en sus amigos.

[19] En la Europa preindustrial, una gran mayoría de la población vivía en granjas al servicio de señores que no parece que desearan matar de hambre a sus trabajadores, ya que de ellos dependía la producción de su propio alimento. Incluso, si se hubiera dado tal escasez de comida, es complicado que eso afectara a la noción de belleza femenina de los artistas, pues, aun en tiempos de hambruna, 
eran los últimos en pasar necesidad. Además, la estética de la moda era dictada por personas próximas a las clases dominantes, cuyo problema evidentemente no era el hambre.

[20] En este sentido, existe mucha literatura sobre la anorexia mirabilis, referida a las mujeres de la Edad Media en adelante, que se murieron de hambre en nombre de Dios. En nuestra opinión, esta supuesta continuidad es el resultado de una aplicación anacrónica del paradigma moderno de la enfermedad a un contexto histórico donde el ayuno extremo fue considerado una forma legítima de piedad religiosa.

[21] El propio Girard relata cómo vivió en carne propia este rechazo de la experiencia de los otros (Anspach y Tacou, 2009): «Yo era alérgico a toda lectura sugerida por cualquiera. La forma más extrema del mimetismo es el antimimetismo intransigente, pues, si bien es cierto que no hay que ser esclavo de la opinión de los otros, resulta imposible cerrarse a todo lo que venga de fuera. La imitación de los buenos modelos resulta inevitable e incluso indispensable para la creatividad. Al rechazar sistemáticamente todo modelo exterior se corre el riesgo de caer en la esterilidad intelectual» (pp. 83-84).

[22] Así describe el hombre de La Mancha su «despertar a la verdad»: «Yo tengo juicio ya libre y claro, sin las sombras caliginosas de la ignorancia que sobre él me pusieron mi amarga y continua leyenda de los detestables libros de las caballerías. Ya conozco sus disparates y sus embelecos, y no me pesa, sino que este desengaño ha llegado tan tarde, que no me deja tiempo para hacer alguna recompensa leyendo otros que sean luz del alma» (Cervantes, 2005, p. 1093).

[23] Si bien en el mundo occidental prevalece el ideal de la delgadez, varios estudios etnográficos han destacado contextos culturales donde la gordura, en lugar de la delgadez, se asocia con el atractivo, el matrimonio y la fertilidad, así como con atributos como la generosidad, la religiosidad y la preeminencia social (Strand, 2018). En otro sentido, en latitudes no occidentales constatamos un contenido distinto; por ejemplo, tenemos el fenómeno de los atentados suicidas, sean sus motivaciones políticas o religiosas. Tanto en un caso como en otro, estamos ante mártires de la moda. 